\title{
TOURISM AND GROWTH: THE TIMES THEY ARE A-CHANGING
}

This research note investigates the time-varying relationship between tourism and economic growth in Europe. A considerable body of literature attempts to disentangle the connective strands and lines of causality between tourism and the economy. Some authors maintain that tourism leads to economic growth, while others support its antithesis (i.e. it is the economic growth that stimulates tourism growth) (see, inter alia, Parrilla, Font, and Nadal, 2007; Matarrita-Cascante, 2010; Ivanov and Webster, 2012). There are also several studies which suggest either a bidirectional relationship between tourism and the economy or no relationship at all (see, among others, Tang and Jang, 2009; Seetanah, 2011).

The aforementioned studies are confined to static analyses. It is only recently that Arslanturk, Balcilar, and Ozdemir (2011), Lean and Tang (2010) and Tang and Tan (2013) questioned the stability of the tourism-economic growth link over time, although only for Malaysia and Turkey. Given that structural economic changes may alter the relationship between these two series, it is imperative to extend this line of research in other countries. In particular, it is important to examine whether and how recent economic events (e.g. Great Recession of 2007-08 and the Eurozone debt crisis) affect the tourism-economic growth relationship. Therefore, the aim of this study is to examine the time-varying spillover effects between tourism and economic growth in Europe.

To achieve that, we employ the Vector Autoregression-based spillover index approach developed by Diebold and Yilmaz $(2009,2012)$ for six European countries. We include both fragile economies that have been heavily affected by the Great Recession and the Eurozone debt crisis (Greece, Italy, Portugal and Spain) and countries with stronger economic footprint (Austria and Germany). This choice is mainly driven by data availability and the need to include countries with different economic and tourism structures. We use monthly data on seasonally adjusted industrial production indices (as a proxy of economic activity - see, among others, Bjørnland and Leitemo (2009) and Espinoza, Fornari, and Lombardi (2012)) and international tourist arrivals, obtained from Eurostat. All variables are expressed in growth rates. The time range for each country is given in Table 1.

\section{[Insert Table 1 about here]}

The spillover index approach by Diebold and Yilmaz (2009, 2012) builds on the Vector Autoregressive model and variance decompositions. The index allows an assessment of the extent to which each variable's forecast error variance can be explained by shocks to other variables. Using rolling-window estimation, the evolution of spillover effects can be traced over time and illustrated by spillover plots. For the purpose of this study, we use the variant of the spillover index in Diebold and Yilmaz (2012), which extends and generalizes the methodology introduced in Diebold and Yilmaz (2009). This is an appropriate choice because it fully accounts for the observed correlation pattern between tourism and economic growth; as it is difficult, if not impossible, to justify one particular ordering of the tourism and economic growth variables, given the lack of consensus regarding their relationship. 
The total spillover index is defined as:

$$
T S(H)=\frac{\sum_{i, j=1, i \neq j}^{K} \tilde{\phi}_{i j}(H)}{\sum_{i, j=1}^{K} \tilde{\phi}_{i j}(H)} \times 100
$$

which gives the average contribution of spillovers from shocks to all (other) variables to the total forecast error variance. $\tilde{\phi}_{i j}(H)$ is the $H$-step-ahead forecast error variance decomposition based on the generalized Vector Autoregressive framework of Koop, Pesaran, and Potter (1996) and Pesaran and Shin (1998). The directional spillovers received by variable $i$ from all other variables $j$ are defined as: $D S_{i \leftarrow j}(H)=\frac{\sum_{j=1, j \neq i}^{K} \tilde{\phi}_{i j}(H)}{\sum_{i, j=1}^{K} \tilde{\phi}_{i j}(H)} \times 100$, and the directional spillovers transmitted by variable $i$ to all other variables $j$ as: $D S_{i \rightarrow j}(H)=\frac{\sum_{j=1, j \neq i}^{K} \tilde{\phi}_{j i}(H)}{\sum_{i, j=1}^{K} \tilde{\phi}_{j i}(H)} \times 100$. Notice that the set of directional spillovers provides a decomposition of total spillovers into those coming from (or to) a particular source, e.g. from tourism (economic) growth to economic (tourism) growth. By subtracting $D S_{i \leftarrow j}(H)$ from $D S_{i \rightarrow j}(H)$ the net spillover from variable $i$ to variable $j$ is obtained as:

$$
N S_{i}(H)=D S_{i \rightarrow j}(H)-D S_{i \leftarrow j}(H),
$$

providing information on whether tourism or economic growth is a receiver or transmitter of shocks in net terms.

According to Table 2, total spillover indices reveal that on average, there is a weak to moderate interdependence between tourism and economic growth for most countries. The only exceptions are Austria and Portugal which exhibit a moderate level of total spillovers. The average net spillovers demonstrate that tourism is the transmitter of shocks mainly for Italy and to a lesser extent for Germany, Portugal and Spain, given the low net spillover values. The reverse holds true in the cases of Austria and Greece. Thus, on average, a tourism-led economic growth holds for Italy, Germany, Portugal and Spain, whereas an economic-driven tourism growth is evident for Austria and Greece.

\section{[Insert Table 2 about here]}

Although these results reveal some useful information, we should not lose sight of the fact that during the sample period the global economy witnessed some major changes. Thus, it is unlikely that the relationships identified in Table 2 hold for the whole time span investigated here. Hence, a time-varying examination of spillovers is required. Figures 1 and 2 present the 60-month rolling-sample total and net spillover indices, respectively. It is revealed that total spillovers indices fluctuate significantly and the link between tourism and economic growth is heterogeneous across countries and over time. Figure 1 provides the first indication that the nature of the tourism-economic growth relationship is not static.

\section{[Insert Figures 1 and 2 about here]}

Interestingly, almost all sample countries exhibit episodes of either important increases or decreases of the total spillover index. Such observation exposes the existence of two separate clusters. The first cluster comprises Austria and Greece, which experience a sudden decrease in their total spillover index during 2006-2007, i.e. a reduction in the extent of interdependence between the two variables. The second cluster consists of Italy, Portugal and Spain, where a significant increase in their spillover index is observed during 2007-2008. This is evidence of a structural break in the tourism-economic growth link during and after the Great Recession, 
although not in the same direction for all sample countries. Germany is marked off from these clusters, as it is the only one which presents two important peaks in 2000 and early 2003.

Figure 2 disentangles the direction of interdependence between tourism and economic growth over time, exhibiting the 60-month rolling-sample net spillover indices. Net spillovers document which variable (tourism or economic growth) is the main transmitter/receiver of shocks. According to Figure 2, we can observe the changing nature of causality between tourism and economic growth. There are periods when tourism-led economic growth is evident and other periods that are characterised by economic-driven tourism growth. For example, since the Great Recession and the Eurozone debt crisis, economic growth becomes the main transmitter of shocks to the tourism sector (i.e. economic-driven tourism growth is identified) in Austria, Germany, Greece and Portugal. The reverse causality is identified in Italy and Spain (i.e. tourism-led economic growth is observed considering that the net transmitter is tourism growth during this period).

In conclusion, this study provides important findings which suggest that the tourism-economic growth relationship is not stable over time in terms of both its magnitude and direction. Rather, it is very responsive to major economic events. So, times are indeed a-changing. Thus, further research on the time-varying link between tourism and economic growth and its determinants is called for.

\section{References}

Arslanturk, Y., Balcilar, M., Ozdemir, Z. A., 2011. Time-varying linkages between tourism receipts and economic growth in a small open economy. Economic Modelling 28 (1), 664-671.

Bjørnland, H. C., Leitemo, K., 2009. Identifying the interdependence between US monetary policy and the stock market. Journal of Monetary Economics 56 (2), 275-282.

Diebold, F., Yilmaz, K., 2009. Measuring financial asset return and volatility spillovers, with application to global equity markets. Economic Journal 119 (534), 158-171.

Diebold, F. X., Yilmaz, K., 2012. Better to give than to receive: Predictive directional measurement of volatility spillovers. International Journal of Forecasting 28 (1), 57-66.

Espinoza, R., Fornari, F., Lombardi, M. J., 2012. The role of financial variables in predicting economic activity. Journal of Forecasting 31 (1), 15-46.

Ivanov, S., Webster, C., 2012. Tourism's impact on growth: the role of globalisation. Annals of Tourism Research 41, 231-236.

Koop, G., Pesaran, M. H., Potter, S. M., 1996. Impulse response analysis in nonlinear multivariate models. Journal of Econometrics 74 (1), 119-147.

Lean, H. H., Tang, C. F., 2010. Is the tourism-led growth hypothesis stable for Malaysia? A note. International Journal of Tourism Research 12 (4), 375-378.

Matarrita-Cascante, D., 2010. Beyond growth: Reaching tourism-led development. Annals of Tourism Research 37 (4), 1141-1163.

Parrilla, J. C., Font, A. R., Nadal, J. R., 2007. Tourism and long-term growth a Spanish perspective. Annals of Tourism Research 34 (3), 709-726.

Pesaran, H. H., Shin, Y., 1998. Generalized impulse response analysis in linear multivariate models. Economics Letters 58 (1), 17-29.

Seetanah, B., 2011. Assessing the dynamic economic impact of tourism for island economies. Annals of Tourism Research 38 (1), 291-308.

Tang, C. F., Tan, E. C., 2013. How stable is the tourism-led growth hypothesis in Malaysia? Evidence from disaggregated tourism markets. Tourism Management 37, 52-57.

Tang, C.-H. H., Jang, S. S., 2009. The tourism-economy causality in the United States: A sub-industry level examination. Tourism Management 30 (4), 553-558. 
Table 1: Data Availability

\begin{tabular}{lc}
\hline \hline Country & Period \\
AUT & $1996 \mathrm{M} 1-2012 \mathrm{M} 12$ \\
GER & $1995 \mathrm{M} 1-2012 \mathrm{M} 12$ \\
GRC & $1995 \mathrm{M} 3-2012 \mathrm{M} 12$ \\
ITA & $1995 \mathrm{M} 1-2012 \mathrm{M} 12$ \\
PRT & $2000 \mathrm{M} 1-2012 \mathrm{M} 12$ \\
ESP & $1995 \mathrm{M} 3-2012 \mathrm{M} 12$ \\
\hline
\end{tabular}

Table 2: Spillover Table

\begin{tabular}{|c|c|c|c|c|c|c|c|}
\hline Austria & IP & TA & & Germany & IP & TA & \multirow{5}{*}{$\begin{array}{l}\text { Total spillover } \\
\text { index: } 2.65 \%\end{array}$} \\
\hline IP & 94.7 & 5.30 & \multirow{4}{*}{$\begin{array}{l}\text { Total spillover } \\
\text { index: } 8.60 \%\end{array}$} & IP & 96.60 & 3.40 & \\
\hline TA & 11.90 & 88.10 & & TA & 1.90 & 98.10 & \\
\hline Contr. TO others & 11.90 & 5.30 & & Contr. TO others & 1.90 & 3.40 & \\
\hline Net spillovers & 6.60 & -6.60 & & Net spillovers & -1.50 & 1.50 & \\
\hline Greece & $\overline{\mathrm{IP}}$ & $\overline{\mathrm{TA}}$ & \multirow{4}{*}{$\begin{array}{l}\text { Total spillover } \\
\text { index: } 3.30 \%\end{array}$} & Italy & $\overline{\mathrm{IP}}$ & $\overline{\mathrm{TA}}$ & \multirow{4}{*}{$\begin{array}{c}\text { Total spillover } \\
\text { index: } 5.75 \%\end{array}$} \\
\hline Contr. TO others & 6.50 & 0.10 & & Contr. TO others & 3.90 & 7.60 & \\
\hline Contr. incl. own & 106.40 & 93.60 & & Contr. incl. own & 96.30 & 103.70 & \\
\hline Net spillovers & 6.40 & -6.40 & & Net spillovers & -3.70 & 3.70 & \\
\hline Portugal & IP & TA & \multirow{2}{*}{$\begin{array}{l}\text { Total spillover } \\
\text { index: } 8.05 \%\end{array}$} & Spain & IP & TA & \multirow{2}{*}{$\begin{array}{l}\text { Total spillover } \\
\text { index: } 3.75 \%\end{array}$} \\
\hline $\mathrm{IP}$ & 91.60 & 8.40 & & IP & 95.90 & 4.10 & \\
\hline
\end{tabular}

Note: IP and TA denote Industrial Production growth and Tourist Arrivals growth, respectively. 
Figure 1: Total Spillovers of tourism and economic growth
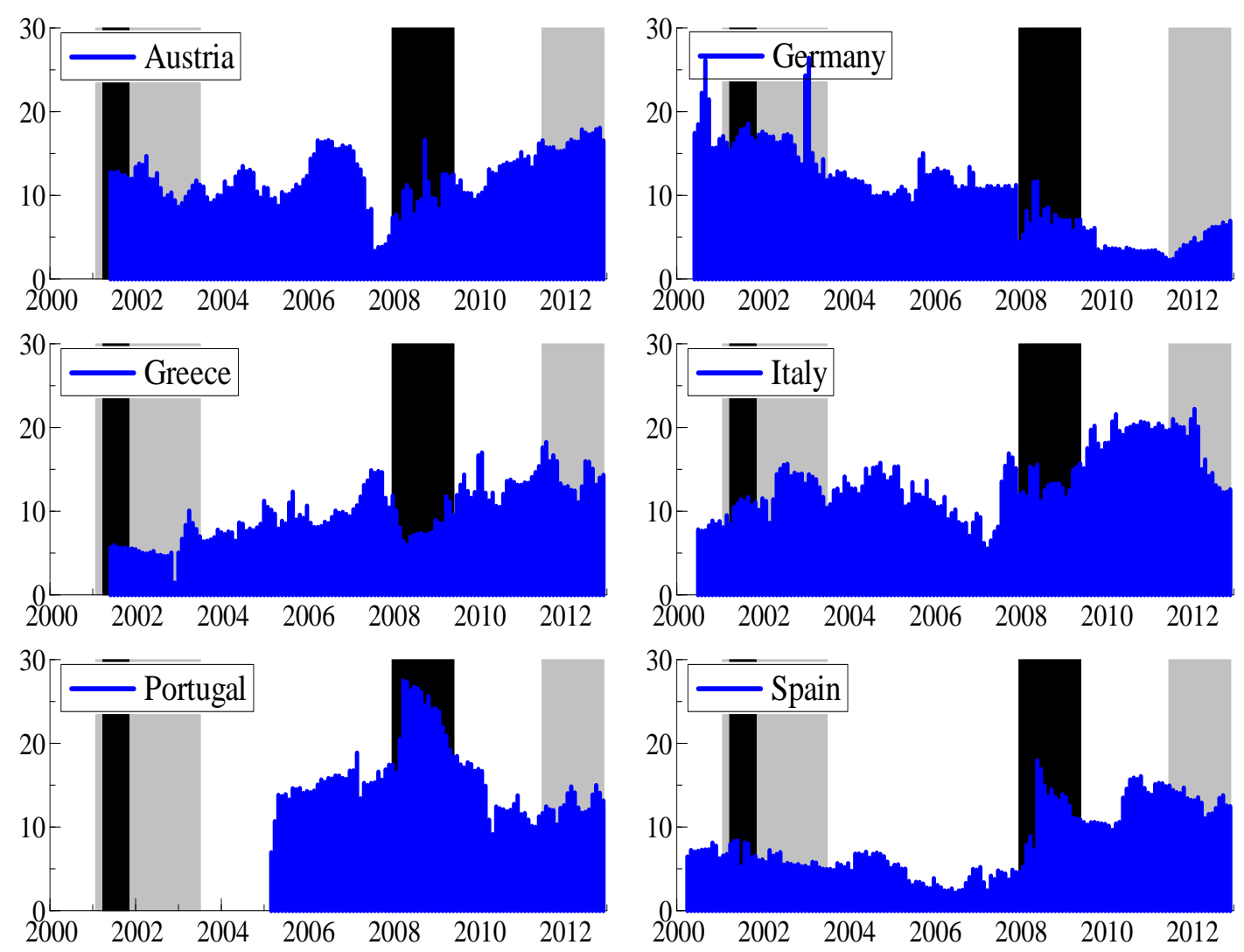

Note: Plots of moving total spillovers estimated using 60 -month rolling windows. Thus the starting date of the total spillover indices is 60 months after the initial available date for each country. Grey and black shading denote euro area and US recessions, respectively. Y-axis represents spillovers in percentage terms. 
Figure 2: Net Spillovers between tourism and economic growth
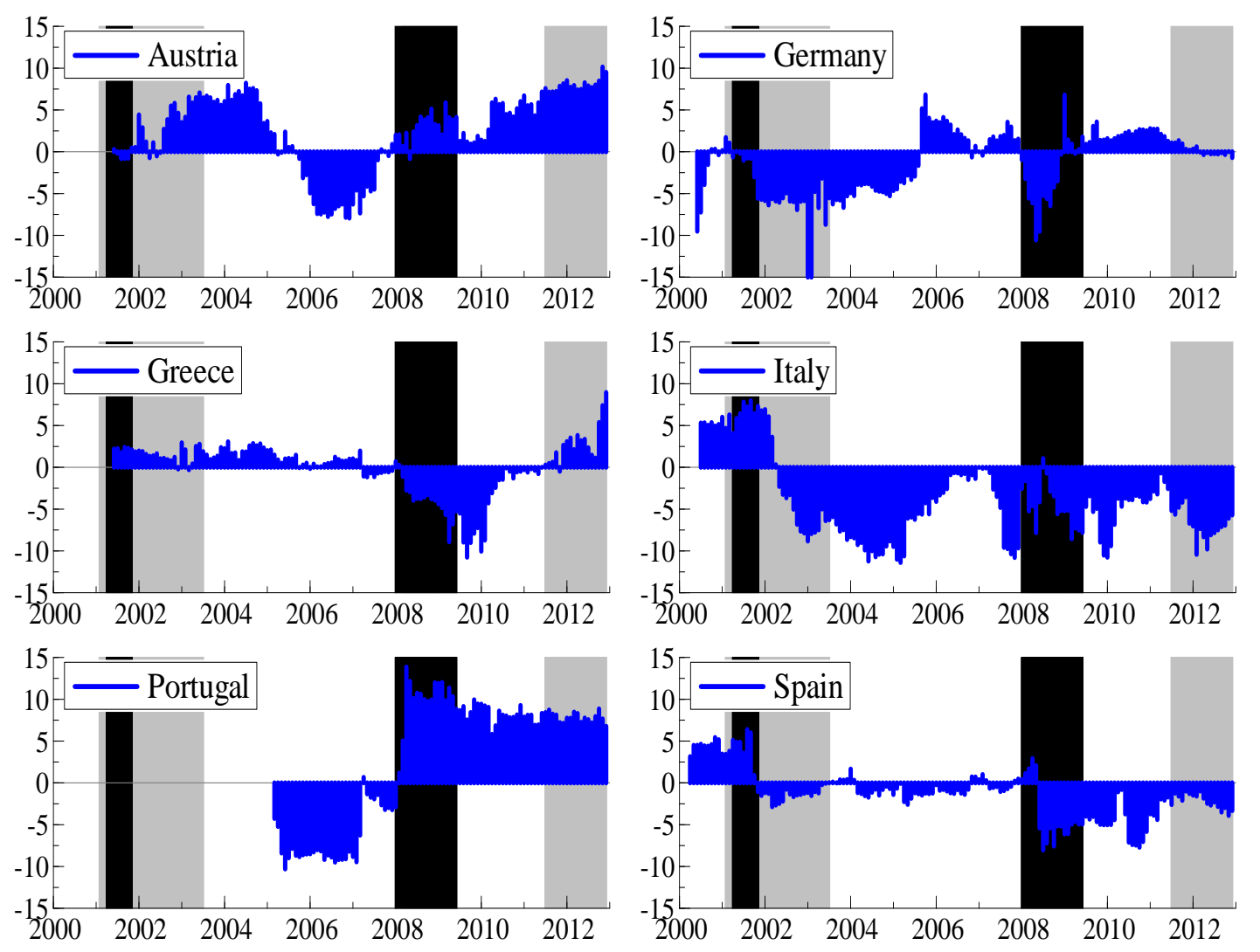

Note: Plots of moving net spillovers estimated using 60-month rolling windows. Thus the starting date of the net spillover indices is 60 months after the initial available date for each country. Positive (negative) values indicate that economic growth (tourism growth) is a net transmitter of shocks to tourism growth (economic growth). Grey and black shading denote euro area and US recessions, respectively. Y-axis represents spillovers in percentage terms. 